\title{
Influence of the Foundation on the Threshold of Stability for Rotating Machines with Roller Bearings-A Theoretical Analysis
}

\author{
Ulrich Werner \\ Faculty of Electrical Engineering, Precision Engineering, Information Technology, Georg Simon Ohm University of Applied \\ Sciences, Nuremberg, Germany \\ Email: ulrich.werner@th-nuernberg.de
}

How to cite this paper: Werner, U. (2017) Influence of the Foundation on the Threshold of Stability for Rotating Machines with Roller Bearings-A Theoretical Analysis. Journal of Applied Mathematics and Physics, 5, 1380-1397.

https://doi.org/10.4236/jamp.2017.56114

Received: May 9, 2017

Accepted: June 27, 2017

Published: June 30, 2017

Copyright $\odot 2017$ by author and Scientific Research Publishing Inc. This work is licensed under the Creative Commons Attribution International License (CC BY 4.0). http://creativecommons.org/licenses/by/4.0/

\begin{abstract}
The paper presents a mathematical model for analyzing the threshold of stability for rotating machines, where the rotor is linked to the stator by roller bearings, bearing housings and end-shields and where the stator feet are mounted on a soft foundation. The internal (rotating) damping of the rotor is the only source of instability, which is considered in the paper. After the mathematical coherences of the multibody model are described, a procedure is presented for deriving the threshold of stability. Additionally, a numerical example is shown, where the threshold of stability is calculated for different boundary conditions. It could be demonstrated, that the stiffness of the foundation-even if the foundation stiffness is isotropic—can help stabilizing this kind of vibration system in the same way as orthotropic bearing stiffness or orthotropic bearing housing and end-shield stiffness for a rigid foundation.
\end{abstract}

\section{Keywords}

Rotordynamics, Instability, Roller Bearings, Rotating Damping

\section{Introduction}

When designing rotating machines, it is important to calculate the vibration behavior and to consider the influence of the foundation [1]-[9]. Beside the forced vibrations-due to e.g. unbalance-also self-excited vibrations have to be considered. There are many effects, which cause self-excited vibrations, e.g. not equal cross-coupling stiffness coefficient in the oil film of sleeve bearings, steam excitations in steam turbines, electromagnetic field damping effects in induction motors, and internal (rotating) damping of the rotor shaft, referring to [3] [4] [5] and [8]. When designing rotating machines, it is important to know, at 
which rotor speed the threshold of rotor stability is reached. If this rotor speed is exceeded, self-excited vibrations are caused, occurring with a natural frequency of the system. This threshold of stability can be pushed to higher rotor speeds, if external damping is added to the rotor, e.g. by squeeze film dampers. But also orthotropic bearing and/or orthotropic support stiffness help to increase the threshold of stability, referring to [1] [2] [3] and [5]. The aim of the paper is now to derive a vibration model for a special kind of rotating machine, where the rotor is linked to the stator by roller bearings, bearing housings and end-shields and where the stator feet are mounted on a soft foundation, so that the centre of gravity of the stator is displaced by the height $h$ from the foundation (Figure 1 ). A soft foundation may be realized by e.g. rubber elements, where the machine is mounted, or by a steel frame foundation, because steel frame foundations are often very flexible, because of economically reasons. Therefore, in the model not only the rotor, the bearings and the support of the bearings are considered, but also the mass and inertia of the stator at its centre of gravity, and the foundation under the machine feet.

\section{Vibration Model}

The vibration model is a simplified model, which describes the movement in the yz-plane (Figure 2). The model is generally based on the model in [9], but modified especially for rotating machines with roller bearings instead of sleeve bearings. The model covers a wide range of rotating machines, and not only electrical machines. Therefore no electromagnetism is here considered, contrarily to [9], where electromagnetic field damping is in the focus. However, the most important difference to [9] is that in this paper here not forced vibrations are analyzed but self-exciting vibrations due to instability, caused by internal (rotating) damping of the rotor shaft.

The vibrations system consists of two main masses, the rotor mass $m_{w}$, which is concentrated as a lumped mass in the middle between the two bearings, and the stator mass $m_{s}$, which is concentrated in the centre of gravity $S$ of the stator with the mass inertia $\theta_{s}$.
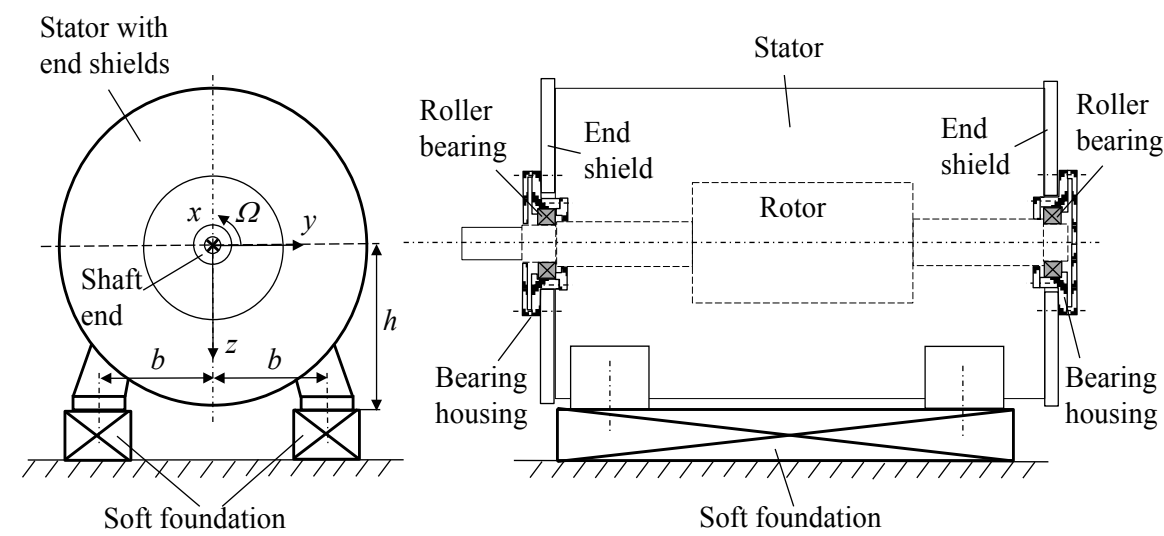

Figure 1. Special kind of rotating machine with rotor, roller bearings, bearing housings, end-shields and stator, mounted on a soft foundation. 


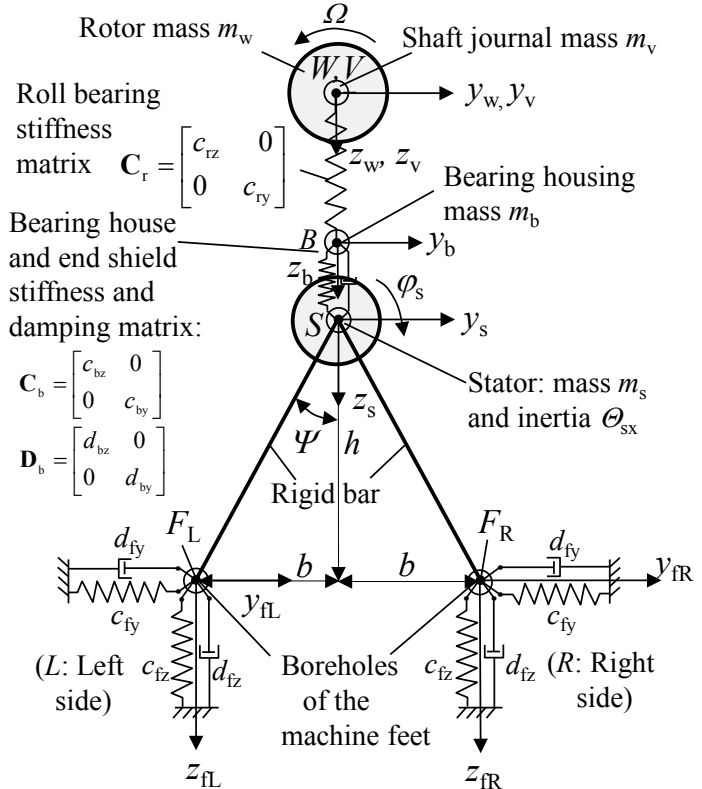

a) View from $x$

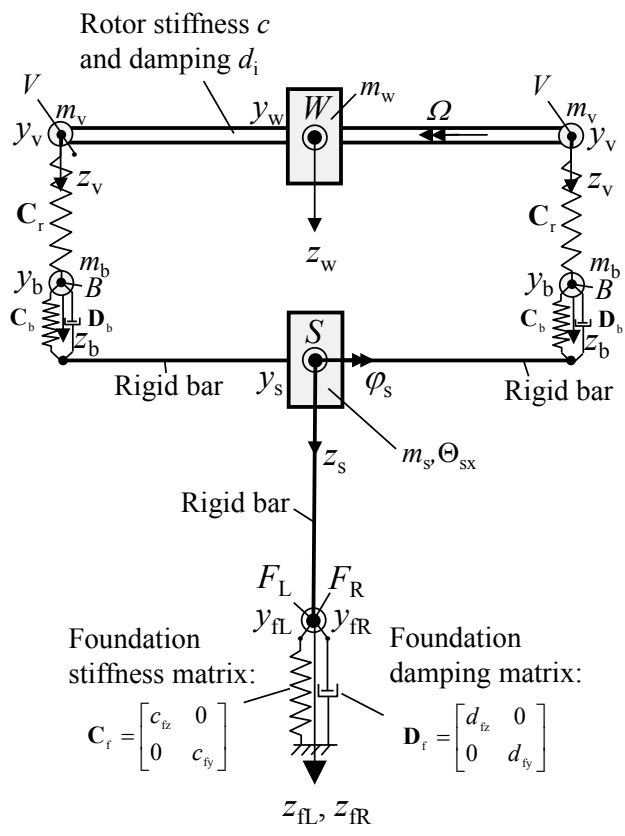

b) View from $y$

Figure 2. Vibration model.

Beside these two main masses, two additionally masses are considered, the mass of the shaft journal $m_{v}$ and the mass of the bearing housing $m_{b}$, mostly to avoid zeros at the main diagonal of the mass matrix. The rotor has the rotor stiffness $c$ and the internal damping $d_{i}$ and rotates with the rotary angular frequency $\Omega$. The rotor is connected to the end-shields by bearing housings and roller bearings, which suppose to be equal for each machine side. Many methods and strategies are described in literature to derive the stiffness of roller bearings, e.g. [10]-[20]. In this paper, a simplified bearing model is used, where the stiffness of the roller bearings is described by the roller bearing stiffness matrix $\boldsymbol{C}_{r}$, with the vertical bearing stiffness $c_{r z}$ and horizontal bearing stiffness $c_{r y}$. Cross coupling coefficients of the roller bearings are neglected as well as damping of the roller bearings. The stiffness and damping of the bearing housing and endshields is described by the bearing housing and end-shield stiffness and damping matrix $\boldsymbol{C}_{b}$ and $\boldsymbol{D}_{b}$, which also suppose to be equal for each machine side. The stator structure is here assumed to be very stiff, compared to the foundation stiffness, so the stator structure can be modeled rigid. The stator feet - $F_{\mathrm{L}}$ (left side) and $F_{\mathrm{R}}$ (right side) - are connected to the ground by the foundation stiffness and damping matrix $\boldsymbol{C}_{f}$ and $\boldsymbol{D}_{f}$, which are also assumed to be equal for the right side and left side of the machine. When deriving the damping coefficients, it has to be considered, that the natural vibration of the critical mode occurs with the angular natural frequency $\omega_{\text {stab }}$ at the threshold of stability, which is the rotary angular frequency $\Omega_{\text {stab }}$. Therefore, the whirling angular frequency $\omega_{F}$ of the rotor becomes $\omega_{\text {stab }}$, at the rotary angular frequency of $\Omega=\Omega_{\text {stab }}$ :

$$
\omega_{F}=\omega_{s t a b}
$$


The internal material damping of the rotor $d_{i}$ can be described by the stiffness of the rotor $c$ and mechanical loss factor $\tan \delta_{i}$ of the rotor, depending on the whirling angular frequency $\omega_{F}$, referring to [3]:

$$
d_{i}\left(\omega_{F}\right)=\frac{c \cdot \tan \delta_{i}}{\omega_{F}}
$$

The same approach is deduced for the damping coefficients of the bearing housing end end-shield and of the foundation:

$$
\begin{gathered}
d_{b z}\left(\omega_{F}\right)=\frac{c_{b z} \cdot \tan \delta_{b}}{\omega_{F}} ; d_{b y}\left(\omega_{F}\right)=\frac{c_{b y} \cdot \tan \delta_{b}}{\omega_{F}} \\
d_{f z}\left(\omega_{F}\right)=\frac{c_{f z} \cdot \tan \delta_{f}}{\omega_{F}} ; d_{f y}\left(\omega_{F}\right)=\frac{c_{f y} \cdot \tan \delta_{f}}{\omega_{F}}
\end{gathered}
$$

With the stiffness of the bearing housing end end-shield $c_{b z}$ and $c_{b y}$ and the stiffness of the foundation at each machine side (left and right side) $c_{f z}$ and $c_{f y}$ and the loss factor of the bearing housing and end-shield $\tan \delta_{b}$ and of the foundation $\tan \delta_{f}$.

\section{Mathematical Model}

To get the threshold of stability, it is necessary to derive the homogenous differential equation by separating the vibration system into four single systems: a) rotor mass system, b) journal system, c) bearing house system and d) stator mass system (Figure 3 ).

a) Rotor mass system

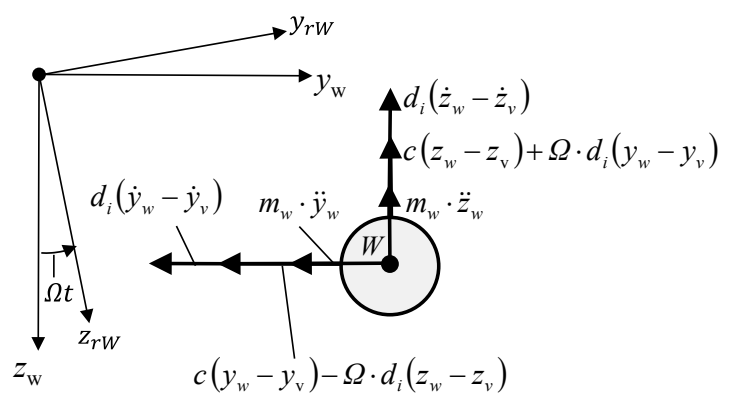

b) Journal system

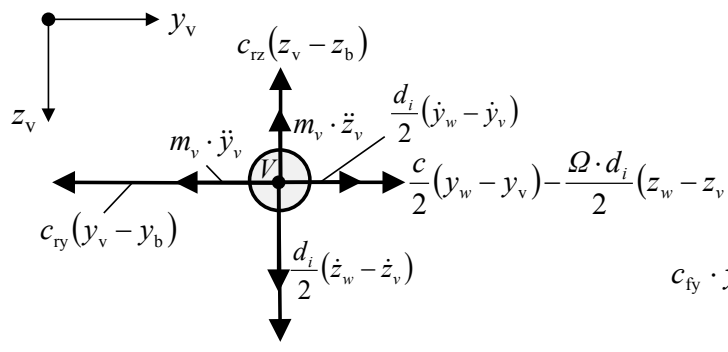

$$
\frac{c}{2}\left(z_{w}-z_{\mathrm{v}}\right)+\frac{\Omega \cdot d_{i}}{2}\left(y_{w}-y_{v}\right)
$$

c) Bearing house system

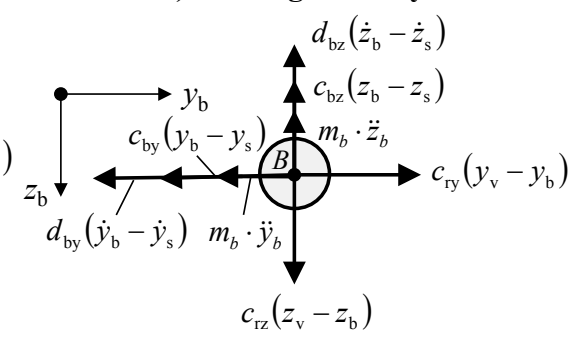

d) Stator mass system

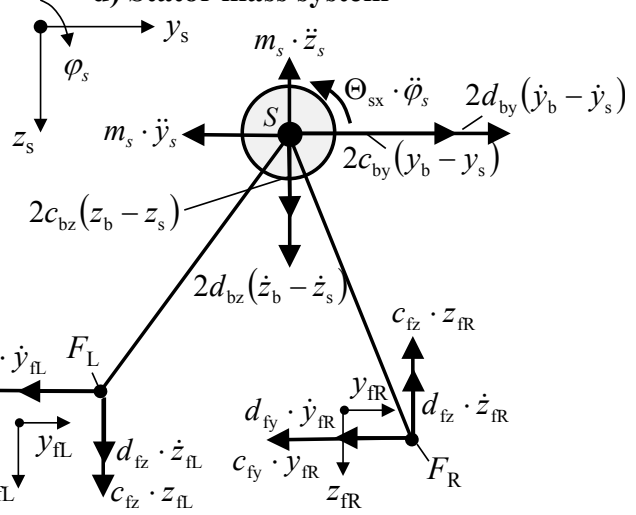

Note: The negative vertical displacement in $F_{L}$, relating to the coordinate $z_{f L}$, is considered by the direction of the vertical forces in $F_{L}$, so $z_{f L}$ has to be described in the differential equation by: $z_{f L}=-z_{s}+\varphi_{s} \cdot b$

Figure 3. Vibration system cut free into subsystems. 
The displacements of the stator mass $\left(z_{s}, y_{s}, \varphi_{s}\right)$ is small, compared to the dimensions of the machine $(h, b, \Psi)$, therefore following linearization is possible:

$$
z_{f L}=z_{s}-\varphi_{s} \cdot b ; z_{f R}=z_{s}+\varphi_{s} \cdot b ; y_{f L}=y_{f R}=y_{s}-\varphi_{s} \cdot h
$$

The homogenous differential equation system can be derived by analyzing the equilibrium of at each single system:

$$
\boldsymbol{M} \cdot \ddot{\boldsymbol{q}}+\boldsymbol{D} \cdot \dot{\boldsymbol{q}}+\boldsymbol{C} \cdot \boldsymbol{q}=\mathbf{0}
$$

with the coordinate vector $\boldsymbol{q}$ :

$$
\boldsymbol{q}=\left[z_{s} ; z_{w} ; y_{s} ; y_{w} ; \varphi_{s} ; z_{v} ; z_{b} ; y_{v} ; y_{b}\right]^{\mathrm{T}}
$$

with the mass matrix $\boldsymbol{M}$ :

$$
\boldsymbol{M}=\left[\begin{array}{ccccccccc}
m_{s} & 0 & 0 & 0 & 0 & 0 & 0 & 0 & 0 \\
0 & m_{w} & 0 & 0 & 0 & 0 & 0 & 0 & 0 \\
0 & 0 & m_{s} & 0 & 0 & 0 & 0 & 0 & 0 \\
0 & 0 & 0 & m_{w} & 0 & 0 & 0 & 0 & 0 \\
0 & 0 & 0 & 0 & \Theta_{s x} & 0 & 0 & 0 & 0 \\
0 & 0 & 0 & 0 & 0 & 2 m_{v} & 0 & 0 & 0 \\
0 & 0 & 0 & 0 & 0 & 0 & 2 m_{b} & 0 & 0 \\
0 & 0 & 0 & 0 & 0 & 0 & 0 & 2 m_{v} & 0 \\
0 & 0 & 0 & 0 & 0 & 0 & 0 & 0 & 2 m_{b}
\end{array}\right]
$$

with the damping matrix $\boldsymbol{D}$ :

$$
\boldsymbol{D}=\left[\begin{array}{ccccccccc}
2\left(d_{f z}+d_{b z}\right) & 0 & 0 & 0 & 0 & 0 & -2 d_{b z} & 0 & 0 \\
0 & d_{i} & 0 & 0 & 0 & -d_{i} & 0 & 0 & 0 \\
0 & 0 & 2\left(d_{f y}+d_{b y}\right) & 0 & -2 d_{f y} \cdot h & 0 & 0 & 0 & -2 d_{b y} \\
0 & 0 & 0 & d_{i} & 0 & 0 & 0 & -d_{i} & 0 \\
0 & 0 & -2 d_{f y} \cdot h & 0 & 2\left(d_{f y} h^{2}+d_{f z} b^{2}\right) & 0 & 0 & 0 & 0 \\
0 & -d_{i} & 0 & 0 & 0 & d_{i} & 0 & 0 & 0 \\
-2 d_{b z} & 0 & 0 & 0 & 0 & 0 & 2 d_{b z} & 0 & 0 \\
0 & 0 & 0 & -d_{i} & 0 & 0 & 0 & d_{i} & 0 \\
0 & 0 & -2 d_{b y} & 0 & 0 & 0 & 0 & 0 & 2 d_{b y}
\end{array}\right]
$$

with the stiffness matrix $\boldsymbol{C}$ :

$\boldsymbol{C}=\left[\begin{array}{ccccccccc}2\left(c_{f z}+c_{b z}\right) & 0 & 0 & 0 & 0 & 0 & -2 c_{b z} & 0 & 0 \\ 0 & c & 0 & \Omega d_{i} & 0 & -c & 0 & -\Omega d_{i} & 0 \\ 0 & 0 & 2\left(c_{f y}+c_{b y}\right) & 0 & -2 c_{f y} h & 0 & 0 & 0 & -2 c_{b y} \\ 0 & -\Omega d_{i} & 0 & c & 0 & \Omega d_{i} & 0 & -c & 0 \\ 0 & 0 & -2 c_{f y} h & 0 & 2\left(c_{f y} h^{2}+c_{f z} b^{2}\right) & 0 & 0 & 0 & 0 \\ 0 & -c & 0 & -\Omega d_{i} & 0 & 2 c_{r z}+c & -2 c_{r z} & \Omega d_{i} & 0 \\ -2 c_{b z} & 0 & 0 & 0 & 0 & -2 c_{r z} & 2\left(c_{r z}+c_{b z}\right) & 0 & 0 \\ 0 & \Omega d_{i} & 0 & -c & 0 & -\Omega d_{i} & 0 & 2 c_{r y}+c & -2 c_{r y} \\ 0 & 0 & -2 c_{b y} & 0 & 0 & 0 & 0 & -2 c_{r y} & 2\left(c_{r y}+c_{b y}\right)\end{array}\right]$


The internal (rotating) damping $d_{i}$ of the rotor in conjunction with the rotary angular frequency $\Omega$ leads here to an anti-symmetric stiffness matrix, which causes instability, when the threshold of stability is exceeded $\left(\Omega>\Omega_{\text {stab }}\right.$ ). The limit of vibration stability $\Omega_{\text {stab }}$ can be calculated, when increasing the rotary angular frequency $\Omega$, and analyzing the eigenvalues. If a real part of one eigenvalue gets zero, the limit of vibration stability is reached. Increasing the rotary angular frequency $\Omega$ furthermore will cause a positive real part and the vibration system gets instable. Using the state-space formulation

$$
\underbrace{\left[\begin{array}{c}
\dot{\boldsymbol{q}}_{h} \\
\ddot{\boldsymbol{q}}_{h}
\end{array}\right]}_{\dot{x}}=\underbrace{\left[\begin{array}{cc}
\mathbf{0} & \boldsymbol{I} \\
-\boldsymbol{M}^{-1} \cdot \boldsymbol{C} & -\boldsymbol{M}^{-1} \cdot \boldsymbol{D}
\end{array}\right]}_{\boldsymbol{A}} \cdot \underbrace{\left[\begin{array}{c}
\boldsymbol{q}_{h} \\
\dot{\boldsymbol{q}}_{h}
\end{array}\right]}_{\boldsymbol{x}}
$$

the eigenvalues can be derived. With the formulation $\boldsymbol{x}=\hat{\boldsymbol{x}} \cdot \mathrm{e}^{\lambda \cdot t}$, the eigenvalues are calculated by:

$$
\operatorname{det}[\boldsymbol{A}-\lambda \cdot \boldsymbol{I}]=0
$$

At the threshold of stability the eigenvalue $\lambda$ of the critical mode gets:

$$
\lambda=\lambda_{\text {stab }}= \pm j \cdot \omega_{\text {stab }}
$$

The real part of the critical eigenvalue $\lambda_{\text {stab }}$ is zero and the whirling angular frequency $\omega_{F}$ is then identical to $\omega_{s t a b}$, while the rotor is rotating with $\Omega_{\text {stab }}$. Considering, that the coefficients $d_{i}, d_{b z}, d_{b y}, d_{f z}, d_{f y}$ are depending on the whirling angular frequency $\omega_{F}$, an iterative solution has to be deduced, according to Figure 4.

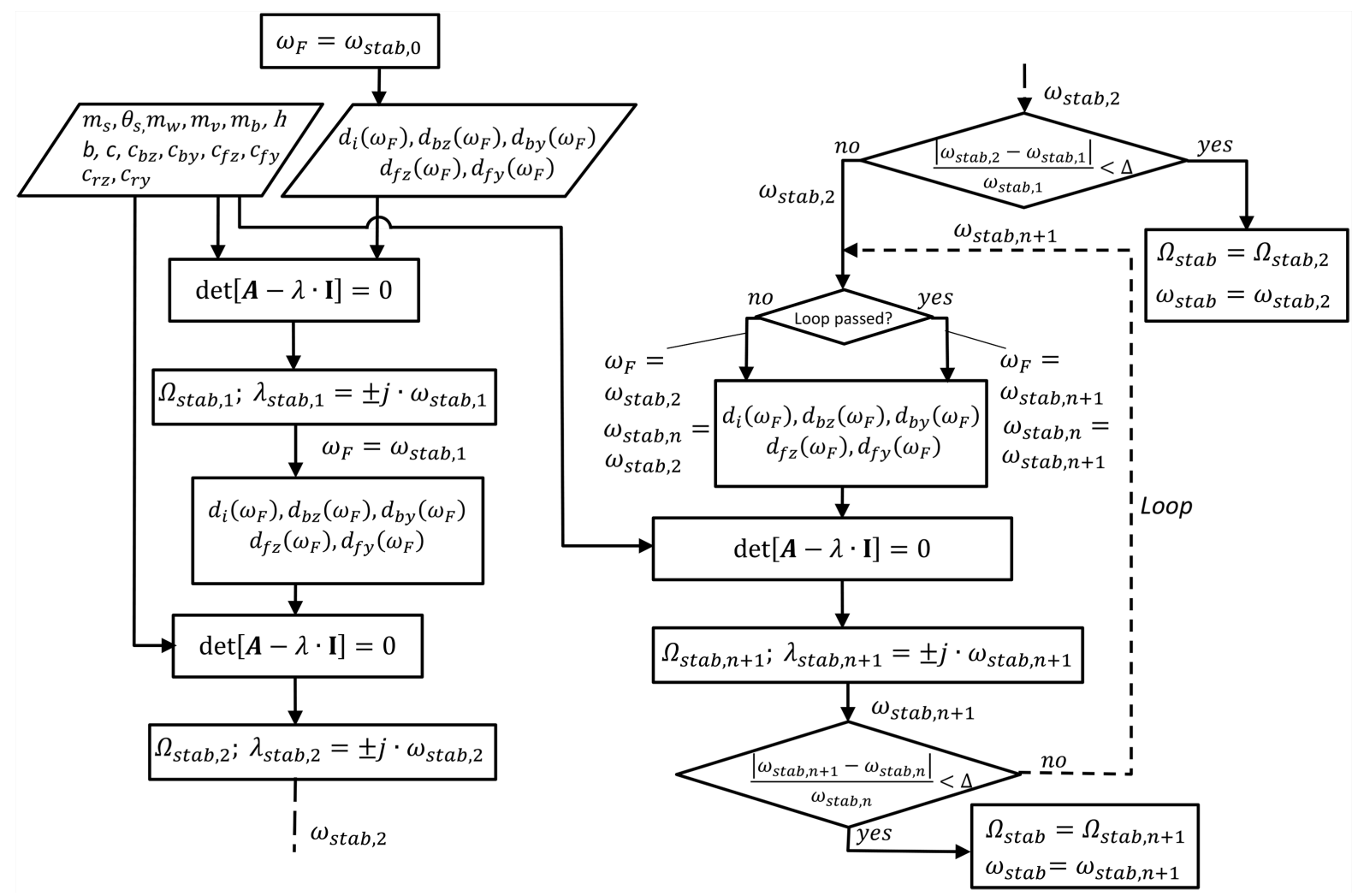

Figure 4. Flow diagram to derive the threshold of stability. 
First, a start value of the whirling angular frequency $\omega_{F}=\omega_{\text {stab }, 0}$ has to be estimated. This can be done e.g. by following estimation, which is based on a ridged mounted machine, without external damping and with the assumption that $c_{r y}<c_{r z}$ and $c_{b y}<c_{b z}$ and that the first natural angular frequency $\omega_{y, 0}$ is here the whirling angular frequency at the threshold of rotor stability:

$$
\omega_{\text {stab }, 0}=\omega_{y, 0}=\sqrt{\frac{c_{\text {total }}}{m_{w}}} \text { with }: c_{\text {total }}=\frac{1}{\frac{1}{c}+\frac{1}{2 c_{r y}}+\frac{1}{2 c_{b y}}}
$$

With this assumption the damping coefficients $d_{i}, d_{b z}, d_{b y}, d_{f z}, d_{f y}$ can be derived, and therefore also the threshold of stability and the natural angular frequency, leading to $\Omega_{\text {stab }, 1}$ and $\omega_{s t a b, 1}$. With this new angular whirling frequency $\omega_{F}=\omega_{s t a b, 1}$ the damping coefficients $d_{i}, d_{b z}, d_{b y}, d_{f z}, d_{f y}$ are calculated again, leading to a new threshold of stability $\Omega_{\text {stab,2 }}$ and a new natural angular frequency $\omega_{s t a b, 2}$. If the ratio $\left|\omega_{s t a b, 2}-\omega_{s t a b, 1}\right| / \omega_{s t a b, 1}$ is less than $\Delta$ an arbitrarily chosen value -the calculation is finished and $\Omega_{\text {stab }}=\Omega_{\text {stab,2 }}$ and $\omega_{\text {stab }}=\omega_{\text {stab }, 2}$. If the ration is larger as the chosen value $\Delta$, a loop has to be run through till the ratio is less than $\Delta$.

\section{Numerical Example}

Based on the mathematical derivation, a numerical example is shown, where the threshold of stability is analyzed.

\subsection{Boundary Conditions}

The rotating machine consists of a rotor, roller bearings, bearing housings, end-shields and a stator (Figure 1), which is mounted on a welded steel frame foundation. The data of the rotating machine, roller bearings and foundation is shown in Table 1.

\subsection{Analysis of Natural Vibrations and Threshold of Stability}

In Figure 5 the real part and the imaginary part of the eigenvalues are presented, depending on the rotor speed.

It can be shown, that at a rotor speed of about $26130 \mathrm{rpm}$ the real part $\alpha_{3}$ becomes zero and therefore the threshold of stability is reached. The corresponding natural angular frequency is $\omega_{3}=394.3 \mathrm{rad} / \mathrm{s}$, which is equal to the whirling angular frequency $\omega_{F}=\omega_{\text {stab }}$ at the limit of stability of the critical mode, which is here mode 3 . Increasing the rotor speed above $26130 \mathrm{rpm}$, leads to instability of the vibration system.

Figure 6 shows the different mode shapes at the threshold of stability ( $n_{\text {stab }}=26130 \mathrm{rpm}$ ). Because of the clarity, only the orbits of the rotor mass, stator mass and machine feet are shown, and not the orbits of the shaft journal points and the bearing housing points. As it can be seen, all eigenvalues of the mode shapes have negative real parts, except mode 3 , where the real part $\alpha_{3}$ is 
Table 1. Data of rotating machine, roller bearings and foundation.

\begin{tabular}{|c|c|c|}
\hline \multirow[t]{2}{*}{ Machine data } & \multirow[b]{2}{*}{ Mass of the stator } & \multirow{2}{*}{$\begin{array}{c}\text { Value } \\
m_{s}=3900 \mathrm{~kg}\end{array}$} \\
\hline & & \\
\hline & Mass inertia of the stator at $x$-axis & $\theta_{s x}=530 \mathrm{~kg} \cdot \mathrm{m}^{2}$ \\
\hline & Mass of the rotor & $m_{w}=930 \mathrm{~kg}$ \\
\hline & Mass of the rotor shaft journal & $m_{v}=5 \mathrm{~kg}$ \\
\hline & Mass of the bearing housing & $m_{b}=20 \mathrm{~kg}$ \\
\hline & Height of the centre of gravity & $h=450 \mathrm{~mm}$ \\
\hline & Distance between motor feet & $2 b=850 \mathrm{~mm}$ \\
\hline & Stiffness of the rotor & $c=1.72 \times 10^{8} \mathrm{~kg} / \mathrm{s}^{2}$ \\
\hline & Horizontal stiffness of bearing housing and end shield & $c_{b y}=7.0 \times 10^{8} \mathrm{~kg} / \mathrm{s}^{2}$ \\
\hline & Vertical stiffness of bearing housing and end shield & $c_{b z}=7.0 \times 10^{8} \mathrm{~kg} / \mathrm{s}^{2}$ \\
\hline & Mechanical loss factor of bearing housing and end shield & $\tan \delta_{b}=0.04$ \\
\hline & Mechanical loss factor of the rotor & $\tan \delta_{i}=0.03$ \\
\hline Bearing data & Description & Value \\
\hline & Bearing type & Ball bearing; Type $6220 \mathrm{C} 3$ \\
\hline & Horizontal stiffness of the roller bearing & $c_{r y}=2.0 \times 10^{8} \mathrm{~kg} / \mathrm{s}^{2}$ \\
\hline & Vertical stiffness of the roller bearing & $c_{r z}=2.0 \times 10^{8} \mathrm{~kg} / \mathrm{s}^{2}$ \\
\hline Foundation data & Description & Value \\
\hline & Type of foundation & Welded steel frame foundation \\
\hline & Vertical stiffness of the foundation at each motor side & $c_{f z}=1.5 \times 10^{8} \mathrm{~kg} / \mathrm{s}^{2}$ \\
\hline & Horizontal stiffness of the foundation at each motor side & $c_{f y}=1.0 \times 10^{8} \mathrm{~kg} / \mathrm{s}^{2}$ \\
\hline & Mechanical loss factor of the foundation & $\tan \delta_{f}=0.04$ \\
\hline
\end{tabular}

zero. When increasing the rotor speed furthermore, this real part $\alpha_{3}$ gets positive. Therefore mode 3 is the critical mode shape.

\subsection{Variation of Single Parameters}

Now different cases are investigated, and the threshold of stability $n_{\text {stab }}$ is calculated as well as the natural angular frequency $\omega_{\text {stab }}$ at the threshold of stability (Table 2).

Table 2 shows, that neglecting the damping of the bearing housings and end shields (case $b$ ) only decreases here the threshold of stability $n_{\text {stab }}$ marginal $(-1.07 \%)$. Without foundation damping (case $c$ ) a clearly reduction of $n_{\text {stab }}$ is obvious $(-4.82 \%)$. A strong reduction occurs, if the foundation would be rigid (cases $d$ ). Here the threshold of stability occurs already at a rotor speed of 3840 rpm, which means a reduction of $-85.3 \%$. 


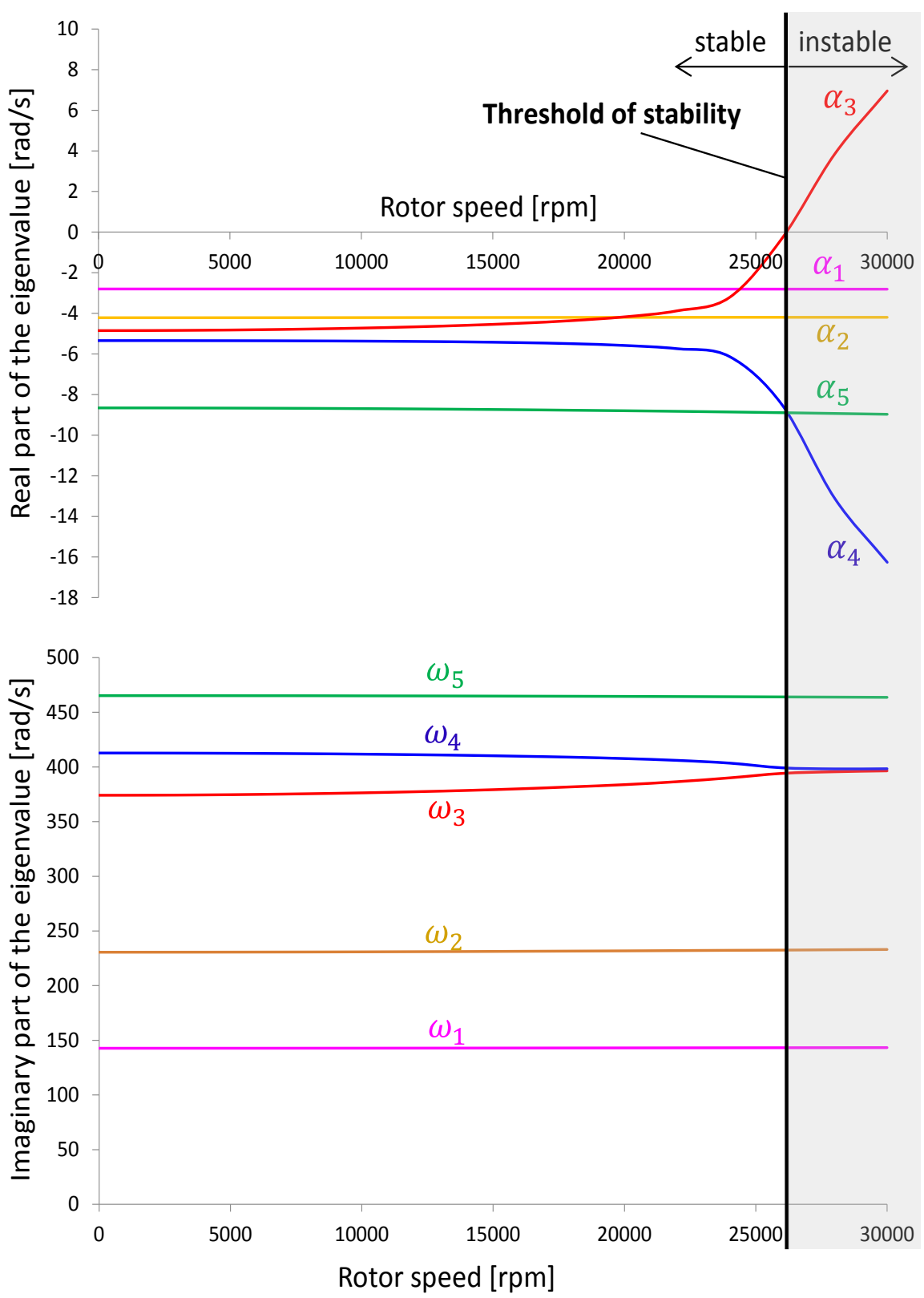

Figure 5. Eigenvalues, depending on the rotor speed and threshold of stability.

If then the bearing stiffness would be changed from isotropic $\left(c_{r z}=c_{r y}=2.0\right.$ $\left.\times 10^{8} \mathrm{~kg} / \mathrm{s}^{2}\right)$ to orthotropic $\left(c_{r z} \neq c_{r y} ; \quad c_{r y}=1.5 \times 10^{8} \mathrm{~kg} / \mathrm{s}^{2}\right.$ and $c_{r z}=2.5$ $\times 10^{8} \mathrm{~kg} / \mathrm{s}^{2}$ ), the threshold of stability can be increased again up to $13020 \mathrm{rpm}$ (case e).

\subsection{Arbitrarily Variation of Foundation Stiffness}

In this section, the influence of the foundation stiffness on the threshold of stability $n_{\text {stab }}$ and on the whirling angular frequency $\omega_{\text {stab }}$ is analyzed.

Therefore, the foundation stiffness is variated from the rated values in Table 1 with factors between 0.2 and 5 , which means, that the foundation stiffness is variated in a range between $2 \times 10^{7} \mathrm{~kg} / \mathrm{s}^{2}$ and $7.5 \times 10^{8} \mathrm{~kg} / \mathrm{s}^{2}$ (Figure 7). 
Mode 1:

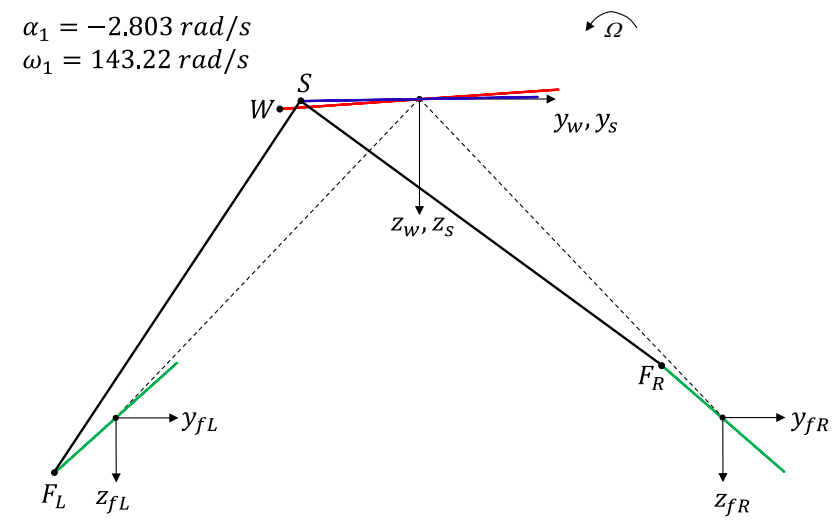

Mode 3:

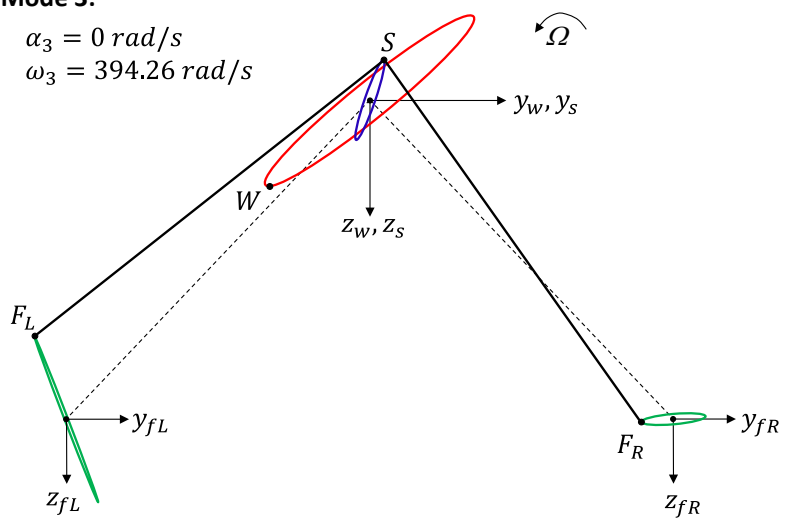

Mode 5:
Mode 2:

$\alpha_{2}=-4.196 \mathrm{rad} / \mathrm{s}$

$\omega_{2}=232.56 \mathrm{rad} / \mathrm{s}$

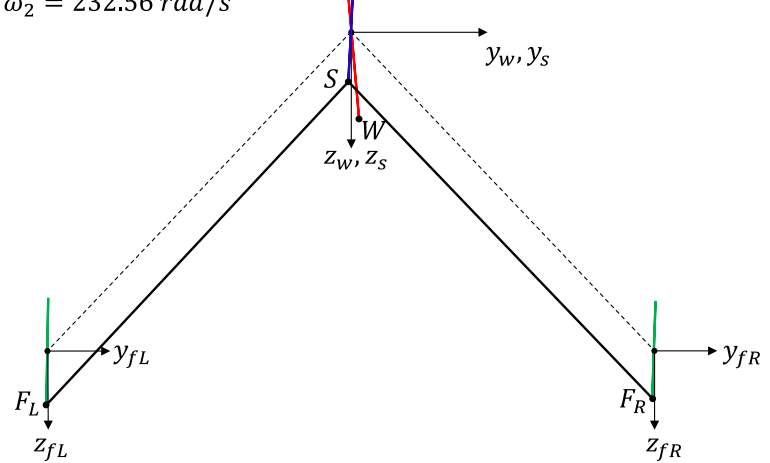

Mode 4:

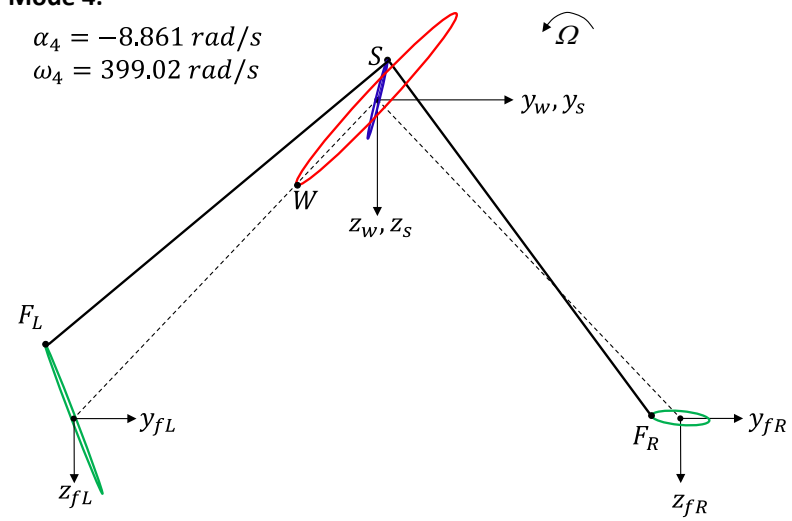

$\widehat{\Omega}$

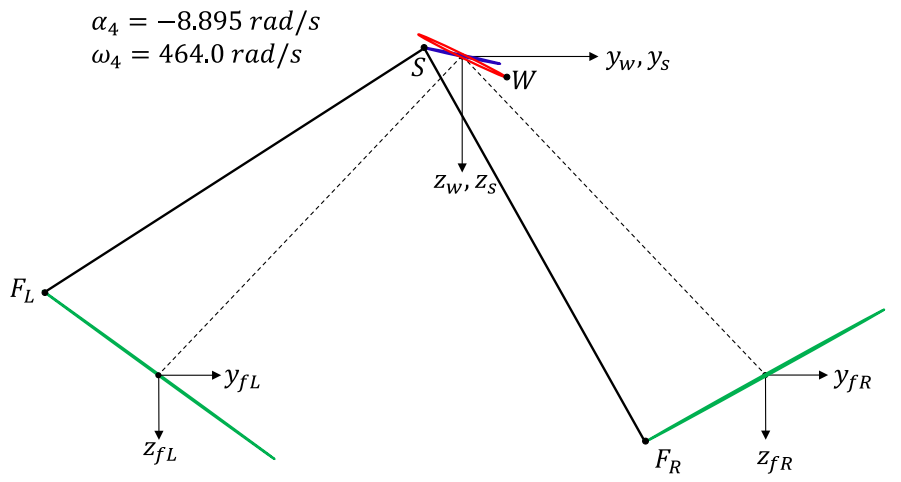

Figure 6. Mode shapes at the threshold of stability with $n_{\text {stab }}=26130 \mathrm{rpm}$.

Table 2. Threshold of stabilty for different cases.

\section{Case Description}

a) Basic Data (Data Table 2)

b) Data Table 2 with $d_{b y}=d_{b z}=0$

(No damping of the bearing housings and end shields)

Data Table 2 with $d_{f y}=d_{f z}=0$

c) (No damping of the foundation)

d) Data Table 2 with $c_{f y}=c_{f z} \rightarrow \infty$ (Infinitely stiff foundation)

e) Data Table 2 with $c_{f y}=c_{f z} \rightarrow \infty$ and $c_{r y}=1.5 \times 10^{8} \mathrm{~kg} / \mathrm{s}^{2} ; c_{r z}=2.5 \times 10^{8} \mathrm{~kg} / \mathrm{s}^{2}$ (Infinitely stiff foundation and orthotropic bearing stiffness)

\begin{tabular}{|c|c|c|}
\hline$\omega_{\text {stab }}[\mathrm{rad} / \mathrm{s}]$ & $n_{\text {stab }} \quad[\mathrm{rpm}]$ & $\Delta$ of $n_{\text {stab }}$ to a) [\%] \\
\hline 394.26 & 26130 & 0 \\
\hline 393.75 & 25850 & -1.07 \\
\hline 391.20 & 24870 & -4.82 \\
\hline 344.85 & 3840 & -85.3 \\
\hline 340.69 & 13020 & -50.2 \\
\hline
\end{tabular}



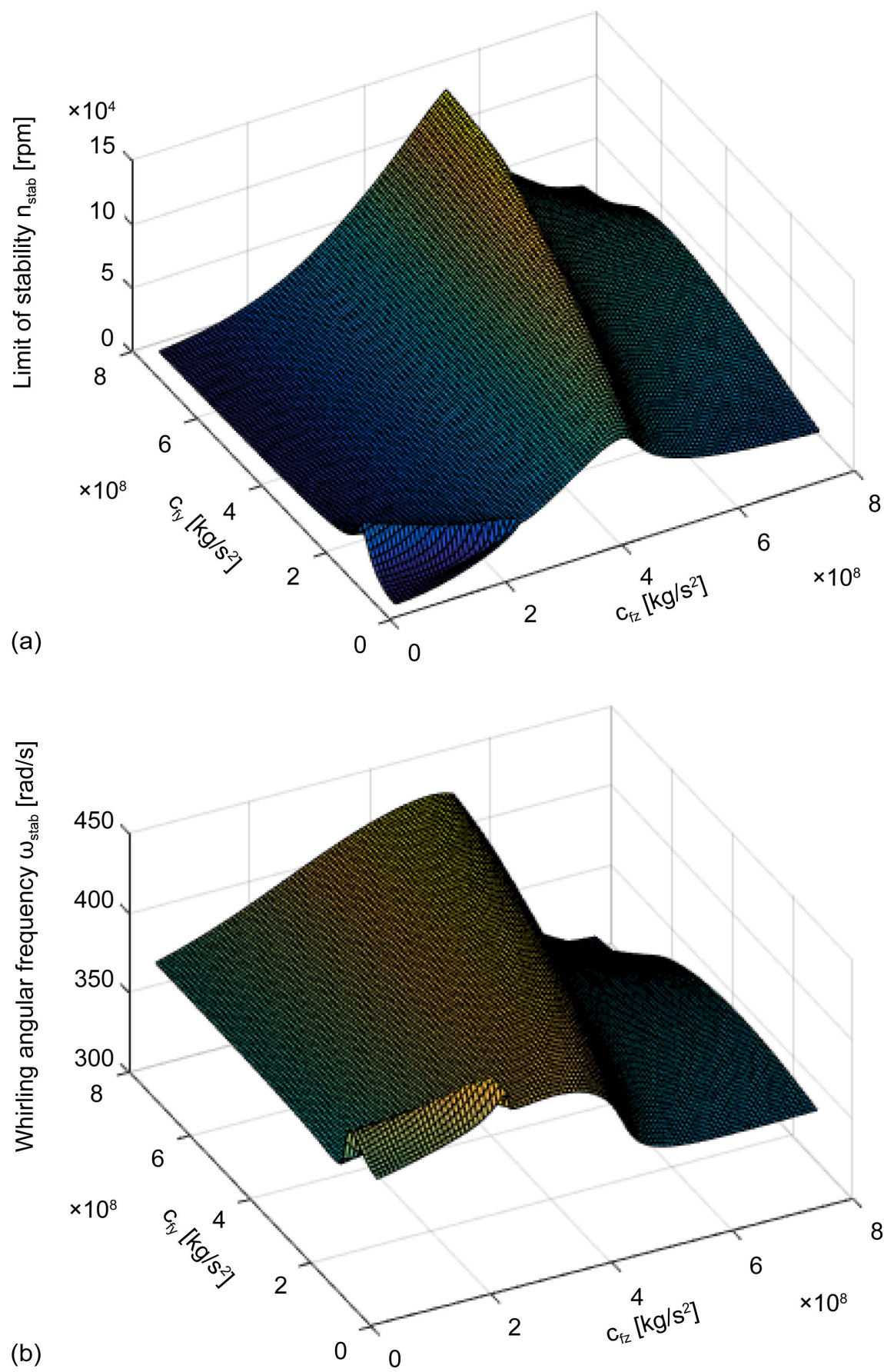

Figure 7. Influence of the foundation stiffness on (a) the limit of stability $n_{\text {stab }}$ and on (b) the whirling angular frequency $\omega_{\text {stab }}$.

\subsection{Arbitrarily Variation of Bearing Stiffness for the Soft Foundation}

Now, the influence of bearing stiffness is analyzed for the rated soft foundation (Table 1). Therefore, the bearing stiffness is variated from the rated values in Table 1 by $\pm 50 \%$, which means that the bearing stiffness is variated in a range between $1 \times 10^{8} \mathrm{~kg} / \mathrm{s}^{2}$ and $3 \times 10^{8} \mathrm{~kg} / \mathrm{s}^{2}$, also considering orthotropic bearing stiffness $\left(c_{r z} \neq c_{r y}\right)$ (Figure 8). 


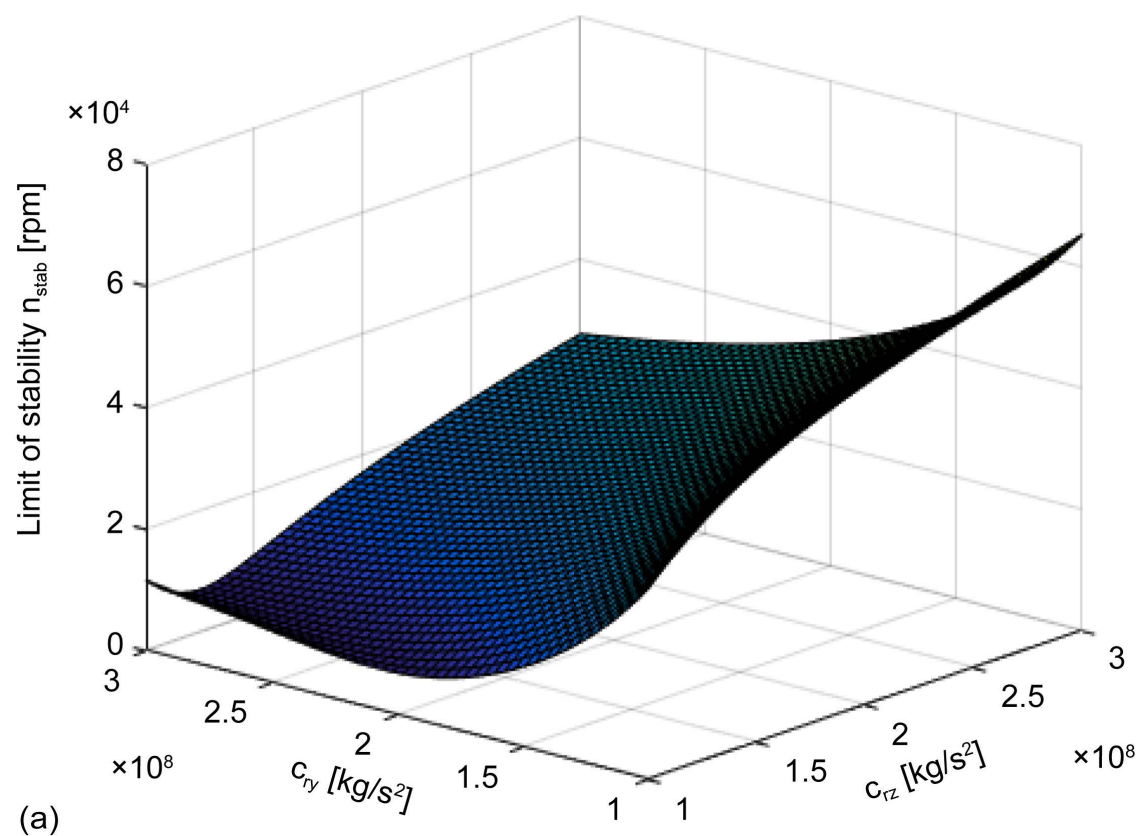

(a)

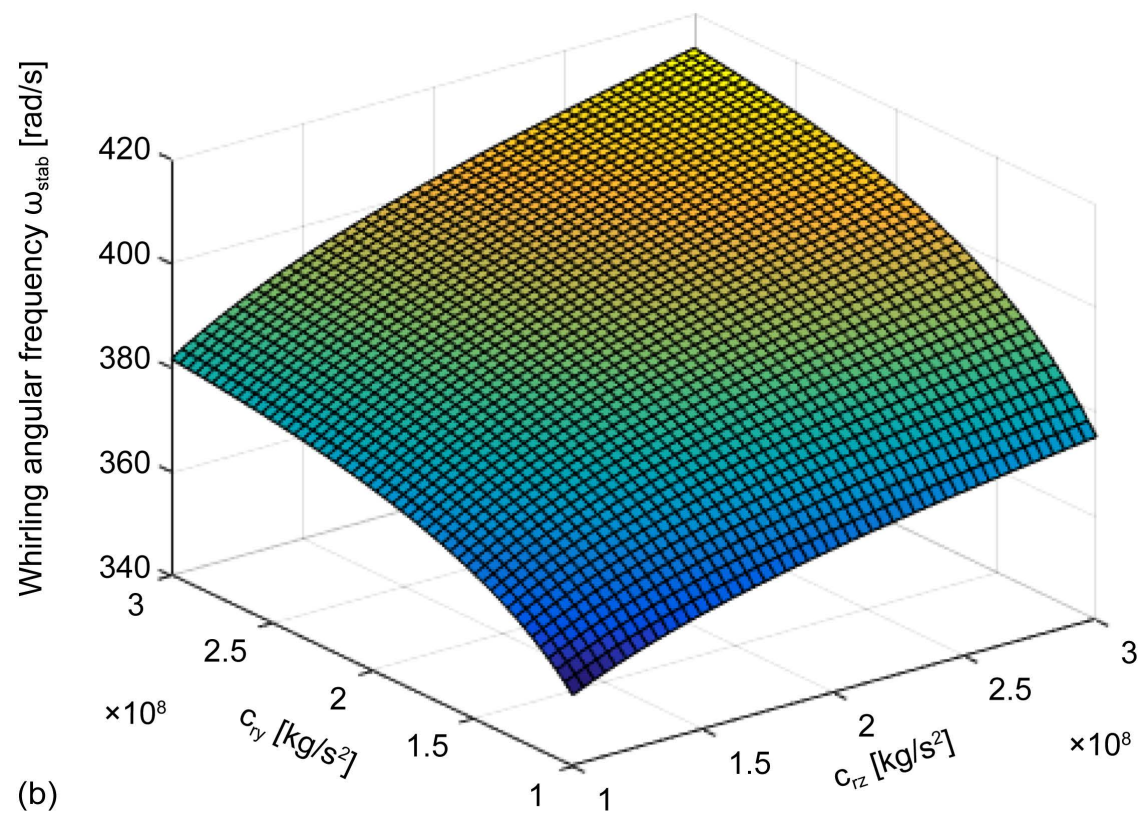

Figure 8. Influence of the bearing stiffness on (a) the limit of stability $n_{\text {stab }}$ and on (b) the whirling angular frequency $\omega_{\text {stab }}$, for the rated soft foundation (Table 1).

\subsection{Arbitrarily Variation of Bearing Housing and End-Shield Stiffness for the Soft Foundation}

In this section, the influence of bearing housing and end-shield stiffness is analyzed, for the rated soft foundation (Table 1). Therefore, the bearing housing and end-shield stiffness is variated from the rated values in Table 1 also by $\pm 50 \%$, which means that the bearing housing and end-shields stiffness is variated in a range between $3.5 \times 10^{8} \mathrm{~kg} / \mathrm{s}^{2}$ and $1.05 \times 10^{9} \mathrm{~kg} / \mathrm{s}^{2}$, also considering orthotropic bearing housing and end-shield stiffness $\left(c_{b z} \neq c_{b y}\right)$ (Figure 9). 


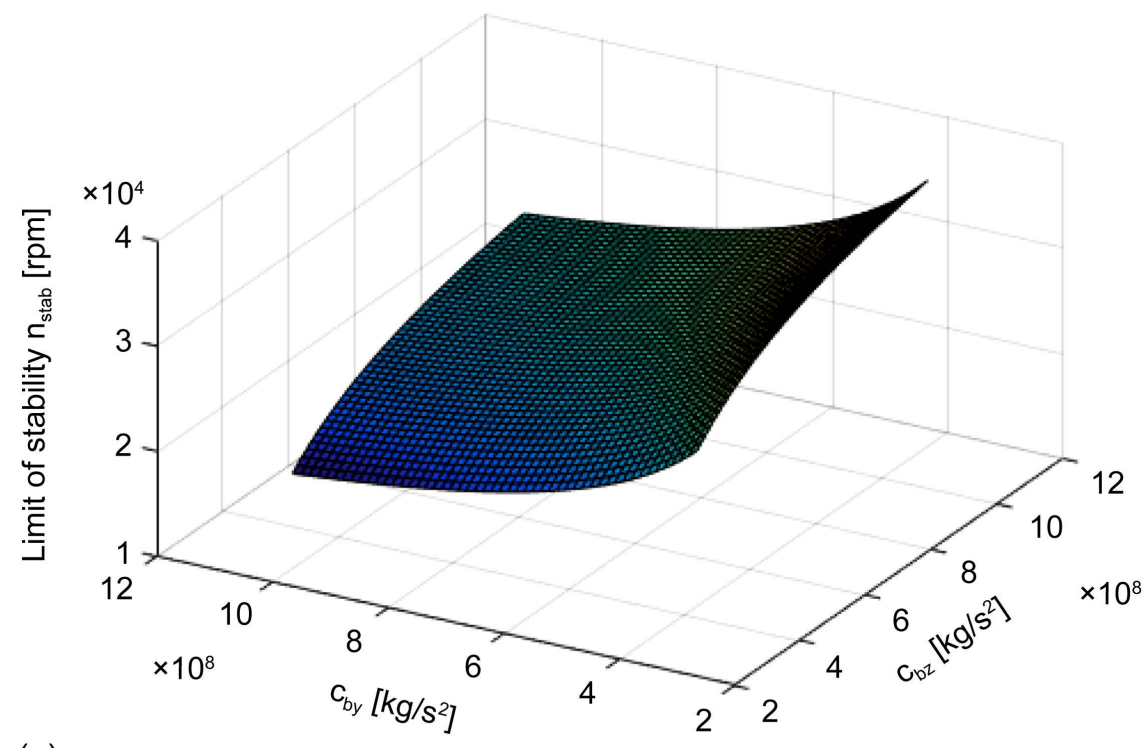

(a)

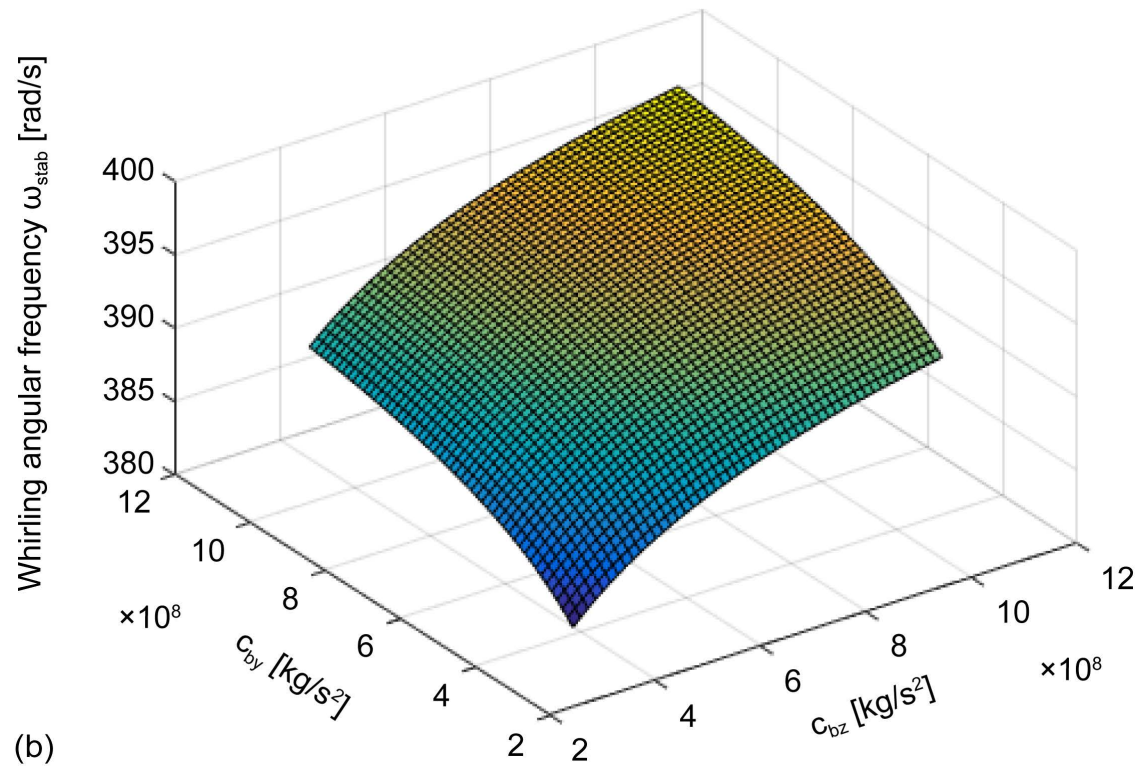

Figure 9. Influence of the bearing housing and end-shield stiffness on (a) the limit of stability $n_{\text {stab }}$ and on (b) the whirling angular frequency $\omega_{\text {stab }}$, for the rated soft foundation (Table 1).

\subsection{Arbitrarily Variation of Bearing Stiffness for a Rigid Foundation}

Here, the influence of the bearing stiffness is analyzed again, but now for a rigid foundation $\left(c_{f z}=c_{f y} \rightarrow \infty\right)$. Therefore, the bearing stiffness is again variated in a range between $1.0 \times 10^{8} \mathrm{~kg} / \mathrm{s}^{2}$ and $3.0 \times 10^{8} \mathrm{~kg} / \mathrm{s}^{2}$ (Figure 10).

\subsection{Arbitrarily Variation of Bearing Housing and End-Shield Stiffness for a Rigid Foundation}

In this section, the influence of bearing housing and end-shield stiffness is analyzed again, but for a rigid soft foundation $\left(c_{f z}=c_{f y} \rightarrow \infty\right)$. Therefore, the 

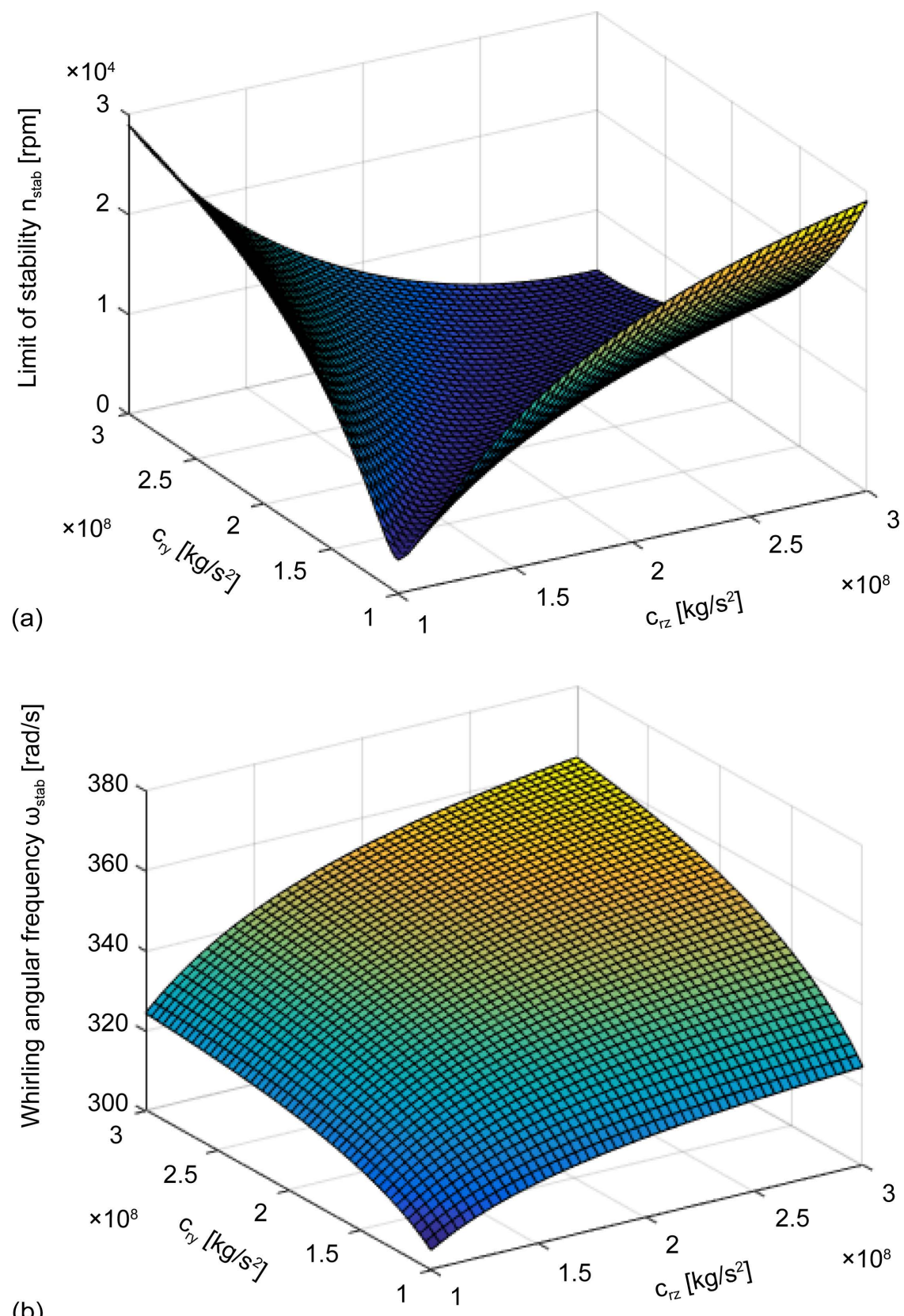

(b)

Figure 10. Influence of the bearing stiffness on (a) the limit of stability $n_{s t a b}$ and on (b) the whirling angular frequency $\omega_{\text {stab}}$, for a rigid foundation.

bearing housing and end-shield stiffness is again variated in a range between $3.5 \times 10^{8} \mathrm{~kg} / \mathrm{s}^{2}$ and $1.05 \times 10^{9} \mathrm{~kg} / \mathrm{s}^{2}$ (Figure 11).

\subsection{Discussions of the Results}

In section $4.4-4.8$ (Figures 7-11) the influence of the foundation stiffness, the bearing stiffness and the bearing housing and end-shield stiffness on the threshold of stability $n_{\text {stab }}$ and on the whirling angular frequency $\omega_{\text {stab }}$ is analyzed. Figure 10 shows, that for a rigid foundation, the threshold of stability can be increased clearly, if orthotropic bearing stiffness $\left(c_{r z} \neq c_{r y}\right)$ exists, which is also 

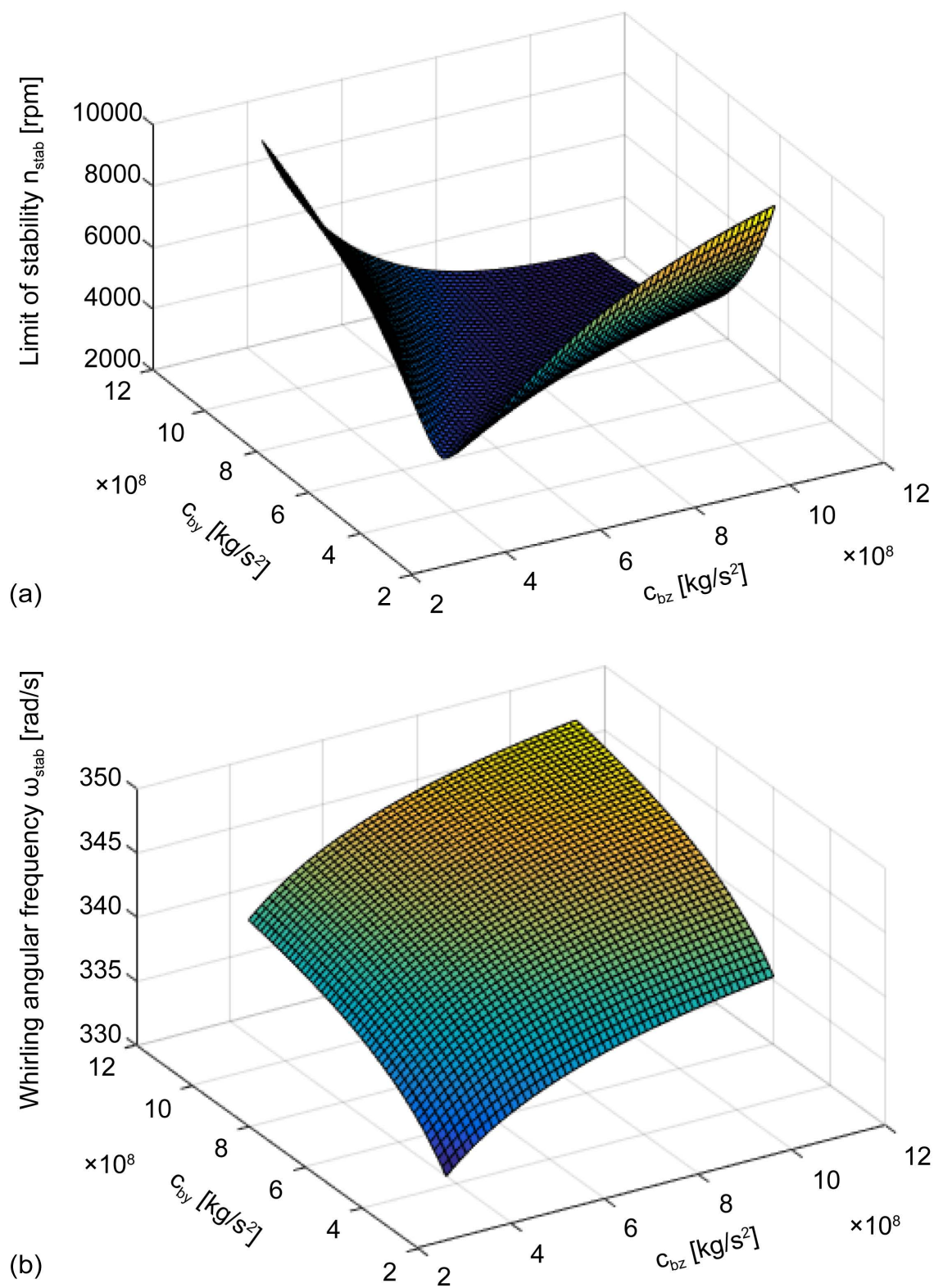

Figure 11. Influence of the bearing housing and end-shield stiffness on (a) the limit of stability $n_{\text {stab }}$ and on (b) the whirling angular frequency $\omega_{\text {stab }}$, for a rigid foundation.

described in literature ([3] [4] [5] and [8]). In this paper the bearing stiffness is variated in the range of $\pm 50 \%$, leading to a maximum threshold of stability of about 29,000 rpm. The same effect is caused, if the bearing housing and endshield stiffness gets orthotropic $\left(c_{b z} \neq c_{b y}\right)$, which can be seen in Figure 11. Here the stiffness is also variated in the range of $\pm 50 \%$, but only leading to a maximum threshold of stability of about $9900 \mathrm{rpm}$. The reason is, that both stiffness, bearing stiffness and bearing housing and end-shield stiffness are connected in series, and the rated bearing stiffness is much lower than the rated bearing housing and end-shield stiffness $\left(c_{r z}=c_{r y}=2.0 \times 10^{8} \mathrm{~kg} / \mathrm{s}^{2}<c_{b z}=c_{b y}=7.0 \times 10^{8} \mathrm{~kg} / \mathrm{s}^{2}\right)$.

The innovation of the paper is now, that it can be demonstrated (Figure 7), that the threshold of stability can also be increased by a soft foundation, even if 
the foundation stiffness is isotropic $\left(c_{f z}=c_{f y}\right)$. The reason is the kind of rotating machine, with a stator, mounted with its feet on a soft foundation, so that the centre of gravity of the stator is displaced by the height $h$ from the foundation (Figure 1). This leads to different mode shapes (Figure 6), which cause a similar effect on the threshold of stability as orthotropic bearing stiffness or orthotropic bearing housing and end-shield stiffness, for a rigid foundation.

In this example, the threshold of stability could be increased even to maximum of about $143000 \mathrm{rpm}$, at a foundation stiffness of $c_{f z}=5.14 \times 10^{8} \mathrm{~kg} / \mathrm{s}^{2}$ and $c_{f y}=7.5 \times 10^{8} \mathrm{~kg} / \mathrm{s}^{2}$ (Figure 7). Increasing the foundation stiffness furthermore in the considered range, leads to a decrease of the threshold of stability, which can be seen in Figure 7. If the foundation stiffness would be increased to infinite, the threshold of stability would drop to $3840 \mathrm{rpm}$ (Table 2; case d). But it has to be considered here, that a boundary condition of the model is, that the stiffness of the stator structure is much higher than the foundation stiffness, so that the stator structure is assumed to be rigid. As a rough estimation: Up to a foundation stiffness of about $c_{f z} \leq 5.0 \times 10^{8} \mathrm{~kg} / \mathrm{s}^{2}$ and $c_{f y} \leq 5.0 \times 10^{8} \mathrm{~kg} / \mathrm{s}^{2}$, this boundary condition is acceptable for this example, above this values the elasticity of the stator structure has to be considered. The influence of bearing stiffness and bearing housing and end-shield stiffness on the threshold of stability for the rated soft foundation is also demonstrated in Figure 8 and Figure 9. In Figure 8 the maximum threshold of stability of about $65200 \mathrm{rpm}$ is reached at a bearing stiffness of $c_{r z}=3.0 \times 10^{8} \mathrm{~kg} / \mathrm{s}^{2}$ and $c_{r y}=1.0 \times 10^{8} \mathrm{~kg} / \mathrm{s}^{2}$. In Figure 9 the maximum threshold of stability of about $37800 \mathrm{rpm}$ is reached at a bearing housing and end-shield stiffness of $c_{b z}=1.05 \times 10^{9} \mathrm{~kg} / \mathrm{s}^{2}$ and $c_{b y}=3.5 \times 10^{8} \mathrm{~kg} / \mathrm{s}^{2}$. Most of the calculated thresholds of stability are fare above the limit of the roller bearings and fare above the limit, what the rotor structure would stand. Additionally it has to be noticed, that with increasing rotor speed, higher bending modes of the rotor become more and more important and therefore also the gyroscopic effect. But of course, this analysis helps to estimate, whether within the rotor speed limits of the roller bearing and of the rotor structure an instability would occur or not, if higher bending modes of the rotor and gyroscopic effects can be neglected.

\section{Conclusion}

The paper presents a mathematical model especially for analyzing the threshold of stability for a special kind of rotating machines, consisting of a rotor, stator, end-shields, bearing housings and roller bearings, mounted on a soft foundation, so that the centre of gravity of the stator is displaced by the height $h$ from the foundation (Figure 1). After the mathematical coherences of the model have been described, a procedure was presented for deriving the threshold of stability. Additionally, a numerical example was shown, where the threshold of stability was calculated for different boundary conditions. The influence of the stiffness of the foundation, of the bearings and of the bearing housings and end-shields was demonstrated, as well as the influence of the damping of the foundation and 
the damping of the bearing housings and end-shields on the threshold of stability. The main task and the innovation of the paper are to demonstrate that for this kind of rotating machines, the stiffness of the soft foundation-even if the foundation stiffness is isotropic-can help stabilizing the vibration system and therefore leading to a similar effect as orthotropic bearing stiffness or orthotropic bearing housing and end-shield stiffness for a rigid foundation. Of course, the presented model is a simplified model of the system, but the conclusions and the procedure for deriving the threshold of stability can also be applied in a finite element analysis. As a future work, experimental validation of the presented theory may be deduced, based e.g. on a small induction motor, to demonstrate the stabilization influence of the foundation.

\section{References}

[1] Kirk, R.G., De Chowdhury, P. and Gunter, E.J. (1974) The Effect of Support Flexibility on the Stability of Rotors Mounted in Plain Cylindrical Bearings. Proceedings of IUTAM Symposium Dynamics of Rotors, Lyngby, Denmark, 244-298.

[2] Gasch, R., Maurer, J. and Sarfeld, W. (1984) The Influence of the Elastic Half Space on Stability and Unbalance of a Simple Rotor-Bearing Foundation System. Proceedings of Conference Vibration in Rotating Machinery, C300/84, Edinburg, UK, 1-12.

[3] Gasch, R., Nordmann, R. and Pfützner, H. (2002) Rotordynamik. Springer-Verlag, Berlin-Heidelberg.

[4] Childs, D.W. (1993) Turbomachinery Rotordynamics: Phenomena, Modeling, and Analysis. John Wiley \& Sons Inc., New York.

[5] Genta, G. (2005) Dynamics of Rotating Systems. Springer Science \& Business Media, New York. https://doi.org/10.1007/0-387-28687-X

[6] Kuemmlee, H., Siegl, G. and Woywode, P. (2008) Influence of Elastic Foundation Structures on the Rotor Dynamics of Drive Trains. Proceedings of Petrol and Chemical Industry Conference EUROPE-Electrical and Instrumentation Applications, Weimar, Germany, 1-8.

[7] Ehehalt, U., Luneburg, B., Staubach, R., Daniel, C., Stackeljan, J. and Woschke, E. (2009) Methods to Incorporate Foundation Elasticities in Rotordynamic Calculations. Proceedings of SIRM $20098^{\text {th }}$ International Conference on Vibrations in Rotating Machines, Vienna, Austria, $10 \mathrm{p}$.

[8] Krämer, E. (1993) Dynamics of Rotors and Foundations. Springer-Verlag, BerlinHeidelberg. https://doi.org/10.1007/978-3-662-02798-1

[9] Werner, U. (2017) Mathematical Multibody Model of a Soft Mounted Induction Motor Regarding Forced Vibrations due to Dynamic Rotor Eccentricities Considering Electromagnetic Field Damping. Journal of Applied Mathematics and Physics, 5, 346-364. https://doi.org/10.4236/jamp.2017.52032

[10] Hamrock, B.J. and Anderson, W.J. (1973) Analysis of an Arched Outer-Race Ball Bearing Considering Centrifugal Forces. ASME Journal of Lubrication Technology, 95, 265-276.

[11] Hernot, X., Sartor, M. and Guillot, J. (2000) Calculation of the Stiffness Matrix of Angular Contact Ball Bearings by Using the Analytical Approach. Journal of Mechanical Design, 122, 83-90. https://doi.org/10.1115/1.533548

[12] Harris, T.A. (2001) Rolling Bearing Analysis. 4th Edition, John Wiley \& Sons, New 
York.

[13] Dougdag, M., Titouche, N.E., Djaoui, M. and Quali, M. (2008) The Calculation of Ball Bearing Nonlinear Stiffness Theoretical and Experimental Study with Comparisons. Journal of Engineering and Applied Science, 3, 872-883.

[14] Guo, Y. and Parker, R.G. (2012) Stiffness Matrix Calculation of Rolling Element Bearings Using a Finite Element/Contact Mechanics Model. Mechanism and Machine Theory, 51, 32-45.

[15] Bauer, C. and Werner, U. (2016) Method to Detect the Critical Bending Speed of an Induction Motor by Using Static Rotor Eccentricity for Deriving the Roller Bearing Stiffness. Proceedings of 11 th International Conference on Vibrations in Rotating Machinery, Manchester, 177-185.

[16] Guay, P. and Frikha, A. (2015) Ball Bearing Stiffness. A New Approach Offering Analytical Expressions. Proceedings of 16th European Space Mechanisms and Tribology Symposium, Bilbao, 23-25 September 2015.

[17] Wu, W., Hong, J., Li, Y. and Li, X. (2017) Investigation of Non-Uniform Preload Effect on Stiffness Behavior of Angular Contact Ball Bearings. Advances in Mechanical Engineering, 9, 1-19. https://doi.org/10.1177/1687814017694118

[18] Nonato, F. and Cavalca, K.L. (2014) An Approach for Including the Stiffness and Damping of Elastohydrodynamics Point Contacts in Deep Groove Ball Bearing Equilibrium Models. Journal of Sound and Vibration, 333, 6960-6978.

[19] Dougdag, M., Ouali, M., Boucherit, H., Titouche, N.E. and Djaoui, M. (2012) An Experimental Testing of a Simplified Model of a Ball Bearing: Stiffness Calculation and Defect Simulation, Meccanica, 47, 335-354.

https://doi.org/10.1007/s11012-011-9434-0

[20] Li, Y., Cao, K. and Zhu, Y. (2013) Study on Nonlinear Stiffness of Rolling Ball Bearing under Varied Operating Conditions. Proceedings of IEEE International Symposium on Assembly and Manufacturing, Xi'an, 30 July-2 August 2013, 8-11.

\section{Scientific Research Publishing}

\section{Submit or recommend next manuscript to SCIRP and we will provide best service for you:}

Accepting pre-submission inquiries through Email, Facebook, LinkedIn, Twitter, etc. A wide selection of journals (inclusive of 9 subjects, more than 200 journals)

Providing 24-hour high-quality service

User-friendly online submission system

Fair and swift peer-review system

Efficient typesetting and proofreading procedure

Display of the result of downloads and visits, as well as the number of cited articles

Maximum dissemination of your research work

Submit your manuscript at: http://papersubmission.scirp.org/

Or contact jamp@scirp.org 